\title{
Selective estrogen receptor modulators as brain therapeutic agents
}

\author{
María Angeles Arevalo, María Santos-Galindo, Natalia Lagunas, Iñigo Azcoitia ${ }^{1}$ \\ and Luis M Garcia-Segura \\ Instituto Cajal, CSIC, Avenida Doctor Arce 37, E-28002 Madrid, Spain \\ ${ }^{1}$ Departamento de Biología Celular, Facultad de Biología, Universidad Complutense de Madrid, E-28040 Madrid, Spain \\ (Correspondence should be addressed to L M Garcia-Segura; Email: Imgs @ cajal.csic.es)
}

\begin{abstract}
Selective estrogen receptor modulators (SERMs), used for the treatment of breast cancer, osteoporosis, and menopausal symptoms, affect the nervous system. Some SERMs trigger neuroprotective mechanisms and reduce neural damage in different experimental models of neural trauma, brain inflammation, neurodegenerative diseases, cognitive impairment, and affective disorders. New SERMs with specific actions on neurons and glial cells may represent promising therapeutic tools for the brain.
\end{abstract}

Journal of Molecular Endocrinology (2011) 46, R1-R9

\section{Introduction}

The neuroprotective potency of estradiol $\left(\mathrm{E}_{2}\right)$ in different animal models of neurodegeneration, cognitive decline, and affective disorders has been extensively characterized in the last decades (Garcia-Segura \& Balthazart 2009). However, the application of $E_{2}$ as a neuroprotectant in humans presents numerous limitations, mainly due to the endocrine actions of the molecule on peripheral tissues, including estrogendependent tumors. The possibility of using selective estrogen receptor modulators (SERMs) to exert $\mathrm{E}_{2}$-like neuroprotective actions in the brain has emerged as an alternative to $\mathrm{E}_{2}$ (DonCarlos et al. 2009). According to chemical family, SERMs are classified as triphenylethylene, benzothiophene, or benzopyran compounds. Triphenylethylene SERMs, such as tamoxifen and its derivatives, are also known as first-generation SERMs. Benzothiophene SERMs include second-generation SERMs, such as raloxifene, and third-generation SERMs. Fourth-generation SERMs are benzopyran compounds (Dowers et al. 2006). SERMs bind to estrogen receptors (ERs) and induce specific changes in their three-dimensional conformation (Brzozowski et al. 1997, Paige et al. 1999) allowing a tissue-selective recruitment of transcriptional cofactors (Norris et al. 1999, Klinge 2000, McKenna \& O’Malley 2002, Belandia \& Parker 2003). Therefore, SERMs may act as ER agonists in the brain and as antagonists in others tissues, such as breast tumors. Here, we will briefly review new advances on the research associated with the potential use of SERMs as neuroprotective agents.

\section{Neuroprotective actions of SERMs}

The neuroprotective actions of tamoxifen and raloxifene, two SERMs that are currently used in clinical practice for the treatment of breast cancer and osteoporosis, have been assessed in different experimental models of neural dysfunction. These include animal models of traumatic injury of the central nervous system and peripheral nerves, stroke, multiple sclerosis, Parkinson's disease, Alzheimer's disease, cognitive decline, and mood disorders (Fig. 1). This section is a succinct description of the main findings of these experimental studies, including the limited available information from human studies.

\section{Brain, spinal cord, and peripheral nerve injury}

Tamoxifen is a protective factor for spinal cord injury. Treatment with tamoxifen, $30 \mathrm{~min}$ after spinal cord injury, results in a decrease in blood spinal cord barrier permeability, reduced edema, reduced microglial activation, decreased myelin and neuronal loss, and 


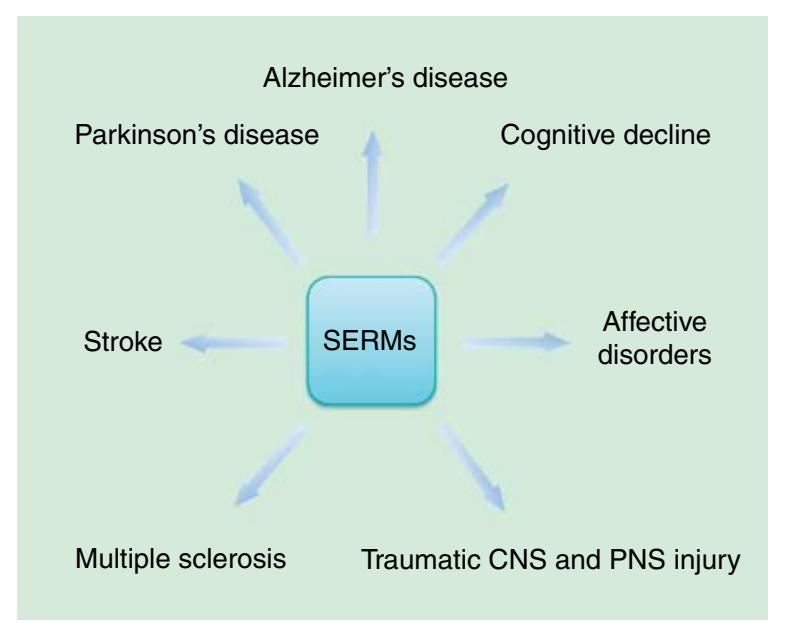

Figure 1 Summary of the neuroprotective effects of SERMs reported in animal models of neurodegenerative, cognitive, and affective disorders.

better functional locomotor recovery (Tian et al. 2009). In addition, tamoxifen and raloxifene reduce reactive gliosis after a traumatic brain injury (Barreto et al. 2009), and raloxifene has been shown to improve functional recovery after bilateral cortical contusion injury (Kokiko et al. 2006). Tamoxifen may also be useful to reduce irradiation-induced brain damage after whole brain irradiation therapy (Liu et al. 2010). SERMs may also have potential application for the regeneration of peripheral nerves, since the raloxifene analog LY117018 increases the number of regenerating nerve fibers after sciatic nerve crush injury in mice (McMurray et al. 2003).

\section{Stroke}

Tamoxifen reduces tissue infarction and behavioral deficits in animal experimental models of stroke (Kimelberg et al. 2003, Mehta et al. 2003, Feng et al. 2004, Kimelberg 2008) and attenuates neuronal excitability impairment caused by ischemic conditions in rat hippocampal slices incubated in oxygen-depleted and glucose-deprived medium (Zhang et al. 2009). The raloxifene analog LY353381.HCl is also neuroprotective in experimental stroke (Rossberg et al. 2000). However, it has been reported that raloxifene may increase the risk of stroke in a subpopulation of women at high stroke risk (Barrett-Connor et al. 2009, Mosca et al. 2009).

\section{Multiple sclerosis}

SERMs may reduce inflammation in the central nervous system (see below) and may therefore represent interesting therapeutic candidates for multiple sclerosis. Indeed, tamoxifen reduces in mice the degree of demyelination caused by experimental autoimmune encephalomyelitis (Bebo et al. 2009).

\section{Parkinson's disease}

Tamoxifen prevents the loss of dopaminergic function in the nigrostriatal system caused by methamphetamine in mice (Mickley \& Dluzen 2004, Bourque et al. 2007). However, the neuroprotective properties of estrogen against Parkinson's disease occurrence may be disrupted by tamoxifen therapy in breast cancer patients (Latourelle et al. 2010). Raloxifene has agonistic estrogenic activity on dopamine receptors (Landry et al. 2002) and protects dopaminergic neurons in experimental animal models of Parkinson's disease (Grandbois et al. 2000, Callier et al. 2001, Morissette et al. 2008).

\section{Alzheimer's disease}

Tamoxifen protects neurons against $\beta$-amyloid toxicity (O'Neill et al. 2004). Some human studies also suggest that tamoxifen may decrease the risk of Alzheimer's disease (Breuer \& Anderson 2000). Raloxifene has been shown to protect PC12 neural cells against $\beta$-amyloid-induced neurotoxicity (Du et al. 2004).

\section{Cognitive decline}

In spite of the neuroprotective actions of tamoxifen in different forms of neural injury, it is unclear whether this molecule may have some benefits for cognition in humans. Indeed, several studies suggest an increased risk of cognitive impairment in women receiving tamoxifen for the treatment of breast cancer, including worse performance in visual memory, word fluency, immediate verbal memory, visuospatial ability, and processing speed tasks (Paganini-Hill \& Clark 2000, Shilling et al. 2003, Palmer et al. 2008, Phillips et al. 2010, Schilder et al. 2010). However, other studies have not detected a significant effect of tamoxifen on cognition (Debess et al. 2010).

In contrast to the potential negative effects of tamoxifen on cognition, the results of the multiple outcomes of raloxifene evaluation randomized trial suggest that raloxifene prevents cognitive decline in postmenopausal women (Yaffe et al. 2005). The results of a recent randomized, double-blind, placebo-controlled trial also suggest that raloxifene improves verbal memory in late postmenopausal women (Jacobsen $\mathrm{et} \mathrm{al}$. 2010). In addition, raloxifene treatment enhances brain activation during performance on a face-encoding paradigm and during recognition of familiar items in healthy elderly men (Goekoop et al. 2005, 2006), 
suggesting that SERMs may also be used to promote cognition in men. In agreement with this possibility, we have recently observed that both tamoxifen and raloxifene improve hippocampus-dependent memory in androgen-deprived male rats ( $\mathrm{N}$ Lagunas, I Calmarza-Font, D Grassi \& LM Garcia-Segura, unpublished observations).

\section{Affective disorders}

Some studies have suggested a potential therapeutic effect of tamoxifen for the treatment of affective disorders. Tamoxifen reduces amphetamine-induced manic-like behavioral alterations in rats (Einat et al. 2007) and reduces acute manic episodes in women with bipolar affective disorder (Kulkarni et al. 2006, Zarate et al. 2007).

Raloxifene reduces anxiety behavior, assessed in the elevated plus maze test, on ovariectomized rats (Walf \& Frye 2010) and decreases anxiety (Strickler et al. 2000, Florio et al. 2001) and depression (Carranza-Lira et al. 2004, Grigoriadis et al. 2005, Sugiyama et al. 2007) in postmenopausal women. Recent clinical studies also suggest the potential application of raloxifene hydrochloride $(120 \mathrm{mg} /$ day oral) for the treatment of postmenopausal women with schizophrenia (Kulkarni et al. 2010).

\section{SERMs and neuroprotection: a summary of the findings}

We can conclude that the studies conducted so far to evaluate the neuroprotective activity of tamoxifen and raloxifene indicate that these SERMs decrease neuronal damage caused by different forms of neural injury in animal models of neurodegenerative diseases. However, animal models of neurodegeneration do not fully reflect the situation in human pathology. Therefore, whether these findings in animals could be translated to human health is still an open question. Nevertheless, the limited information from human studies suggests that SERMs may have a positive impact on mood and cognition, at least under certain circumstances. These findings justify further research on the possible application of SERMs for the treatment of brain disorders.

\section{Molecular mechanisms involved in the neuroprotective actions of SERMs}

SERMs signal on neural cells by multiple mechanisms that may contribute to neuroprotection (Dhandapani \& Brann 2002). Some neuroprotective actions of SERMs may be due to mechanisms independent of their activity as ER modulators. For instance, the efficacy of tamoxifen in the treatment of acute mania has been ascribed to its action as a protein kinase C inhibitor (Einat et al. 2007, Zarate et al. 2007). Other neuroprotective mechanisms of SERMs are mediated by classical ERs, since they are inhibited by ER antagonists, such as ICI 182780 (Zhang et al. 2009). The neuroprotective signaling of SERMs may involve the activation of kinases, such as mitogen-activated protein kinase (MAPK), phosphatidylinositol 3-kinase (PI3K), and Akt (Du et al. 2004, Lee et al. 2009a,b), and the phosphorylation of CREB (Sharma et al. 2007) or the inhibition of nuclear factor (NF)-кB-induced transcription (Cerciat et al. 2010). Through these mechanisms, SERMs control synaptic transmission and the expression of molecules involved in the regulation of cell death, oxidative stress, and inflammation.

We will consider here five important interrelated actions of SERMs in the nervous system that may be highly relevant for their neuroprotective activity: i) the modulation of synaptic transmission; ii) the control of oxidative stress; iii) the control of excitotoxic damage; iv) the control of the apoptotic program; and v) the control of inflammation.

\section{Modulation of synaptic transmission}

Some SERMs promote axonal growth (Nilsen et al. 1998, O'Neill et al. 2004) and the expression of synaptic markers (Sharma et al. 2007), suggesting possible actions on synaptic plasticity and synaptic regeneration. These actions, which are still not sufficiently investigated, may contribute to the maintenance of functional neuronal circuits and to the repair of damaged connectivity. Actions of SERMs on mood and cognition may also be related with their pre- and post-synaptic modulation of cholinergic, serotonergic, and dopaminergic neurotransmission (Wu et al. 1999, Cyr et al. 2000, Smith et al. 2004, Sánchez et al. 2010). Raloxifene may also regulate opiate and GABAergic neurotransmission by the modulation of the levels of $\beta$-endorphin and neuroactive steroids respectively. Chronic raloxifene administration to postmenopausal women increases plasma levels of $\beta$-endorphin and tetrahydroprogesterone (allopregnanolone), an anxiolytic metabolite of progesterone that modulates $\mathrm{GABA}_{\mathrm{A}}$ receptors (Florio et al. 2001, Neele et al. 2002, Bernardi et al. 2003, Genazzani et al. 2003). Changes in the levels of $\beta$-endorphin and tetrahydroprogesterone in plasma probably parallel similar changes in the nervous system, since in ovariectomized rats, the raloxifene analog LY117018 has been shown to increase $\beta$-endorphin and tetrahydroprogesterone levels not only in serum but also in the brain (Genazzani et al. 1999, 2000, Bernardi et al. 2003). These findings suggest that raloxifene may regulate synaptic function by the modulation of local levels of neuroactive substances within the brain. 


\section{Control of oxidative stress}

The well-documented antioxidant effects of tamoxifen, hydroxytamoxifen, and raloxifene in the nervous tissue (Moreira et al. 2004, 2005, Biewenga et al. 2005, Konyalioglu et al. 2007, Armagan et al. 2009) may be relevant for its neuroprotective actions on Parkinson's disease (Lee et al. 2009a,b), cerebral ischemia (Zhang et al. 2007, Wakade et al. 2008), and other neurodegenerative conditions.

\section{Control of excitotoxic damage}

An important neuroprotective action of SERMs is the prevention of excitotoxicity, since this is a common cause of neuronal death in different neurodegenerative disorders. Several SERMs have shown to reduce neuronal loss in the hippocampus after the administration of the excitotoxin kainic acid (Ciriza et al. 2004). Figure 2 shows the effect of tamoxifen, raloxifene, lasofoxifene, and bazedoxifene on hilar neurons of ovariectomized rats injected with kainic acid. Tamoxifen, raloxifene, and bazedoxifene prevent the excitotoxic effect of kainic acid in this model.

\section{Control of the apoptotic program}

The neuroprotective actions of SERMs on excitotoxicity and against other neural insults may be mediated by the regulation of molecules involved in the control of apoptosis. For instance, raloxifene increases the expression of $\mathrm{Bcl}-2$ in the cerebral cortex of ovariectomized rats treated with kainic acid (Armagan et al. 2009), and chronic administration of tamoxifen to ovariectomized rats increases the expression of $\mathrm{Bcl}-2$ and decreases the expression of Bax in the hippocampus (Sharma \& Mehra 2008). Furthermore, tamoxifen and raloxifene up-regulate the expression of the antiapoptotic gene seladin-1 (selective Alzheimer's disease indicator-1) in human neuroblasts (Benvenuti et al. 2005). SERMs may also prevent neuronal apoptosis by the activation of telomerase activity via Akt and the phosphorylation of telomerase catalytic subunit (TERT; Du et al. 2004).

\section{Control of inflammation}

SERMs may also exert neuroprotective actions by the control of local brain inflammation, which is mainly regulated by microglia and astroglia. Tamoxifen and raloxifene are able to decrease the inflammatory response caused by lipopolysaccharide (LPS) in mouse and rat microglia cells in vitro (Suuronen et al. 2005). In addition, these SERMs, at doses within the range used in clinical practice, reduce microglia activation in the central nervous system of male and
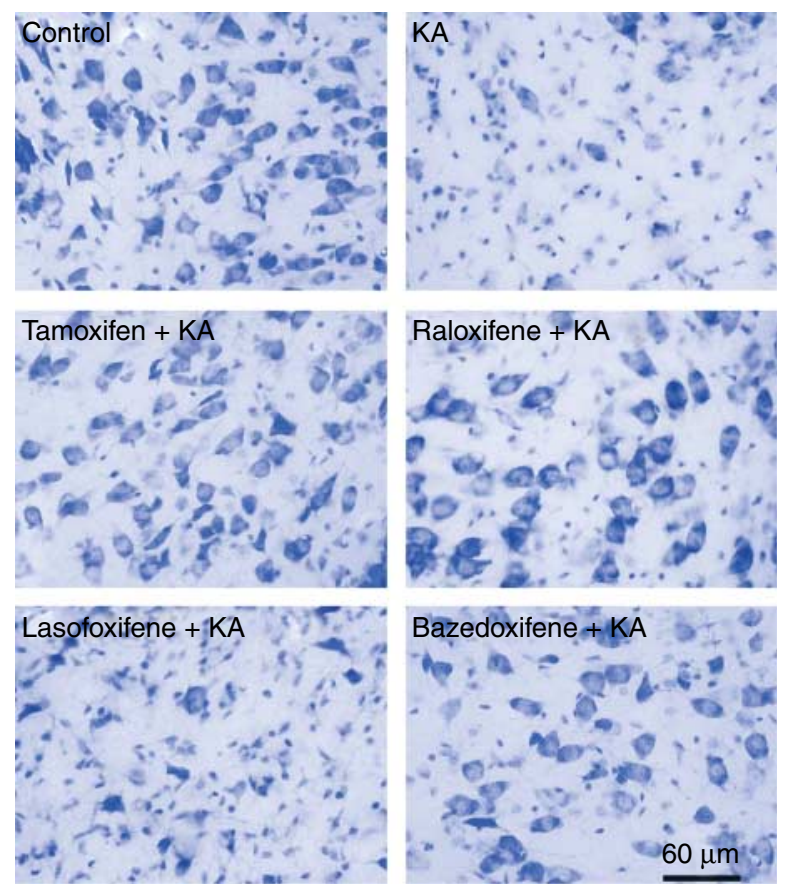

Figure 2 SERMs prevent excitotoxic neuronal death in vivo after kainic acid administration. High magnification of the hilus of the dentate gyrus of ovariectomized rats stained with toluidine blue after the i.p. injection of vehicle (Control); kainic acid (KA; $7 \mathrm{mg} / \mathrm{kg}$ ); tamoxifen (1 mg/kg) and kainic acid; raloxifene $(1 \mathrm{mg} / \mathrm{kg})$ and kainic acid; lasofoxifene $(1 \mathrm{mg} / \mathrm{kg})$ and kainic acid; bazedoxifene $(2 \mathrm{mg} / \mathrm{kg})$ and kainic acid. Kainic acid results in the loss of hilar neurons (large cells). Small cell nuclei correspond to glial cells. Some SERMs, such as tamoxifen, raloxifene, and bazedoxifene, prevent the excitotoxic effect of kainic acid. Adapted, with permission, from Ciriza I, Carrero P, Azcoitia I, Lundeen SG \& Garcia-Segura LM 2004 Selective estrogen receptor modulators protect hippocampal neurons from kainic acid excitotoxicity: differences with the effect of estradiol. Journal of Neurobiology 61 209-221. (C) 2004 Wiley Periodicals, Inc.

female rats in vivo after the peripheral administration of LPS (Tapia-Gonzalez et al. 2008). Figure 3 shows the effect of tamoxifen and raloxifene on microglia activation induced by the systemic administration of LPS. Tamoxifen also reduces microglial inflammatory response induced by irradiation (Liu et al. 2010). In addition, raloxifene decreases the number of astrocytes and microglia in the brain of aged animals (Lei et al. 2003). Furthermore, tamoxifen and raloxifene are able to significantly reduce the number of reactive astrocytes in the hippocampus of young, middle-aged, and older female rats after a stab wound injury (Barreto et al. 2009). Some SERMs have also shown to be able to reduce the inflammatory responses of astrocytes treated with LPS by a mechanism involving ERs and the inhibition of NF- $\kappa \mathrm{B}$-induced transcription of proinflammatory molecules (Cerciat et al. 2010). 

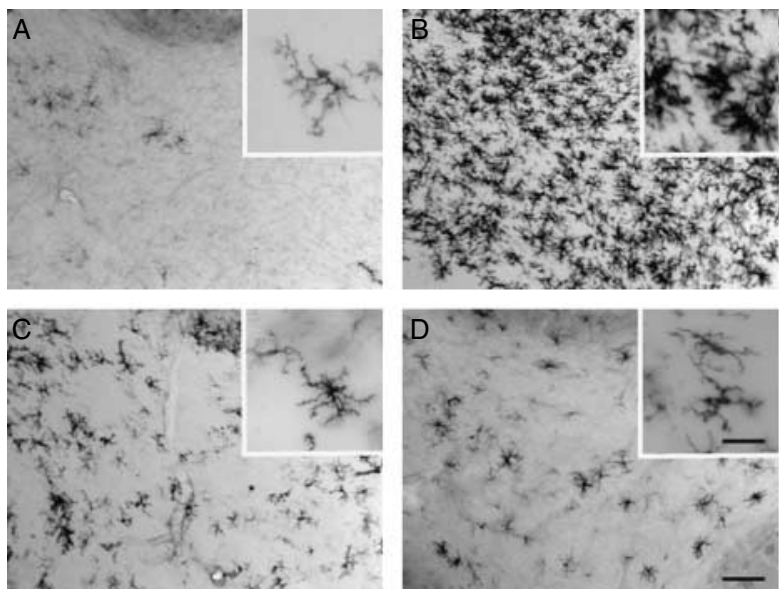

Figure 3 SERMs reduce microglia activation after the administration of LPS in vivo. Representative images of the central white matter of the cerebellum of male rats showing immunoreactivity for MHC-II, a marker of activated microglia, after the i.p. injection of (A) vehicles for SERMs (DMSO) and LPS (phosphate buffer); (B) LPS; (C) $1 \mathrm{mg} / \mathrm{kg}$ tamoxifen and LPS; (D) $1 \mathrm{mg} / \mathrm{kg}$ raloxifene and LPS. Insets show details of the morphology of MHC-II immunoreactive cells at high magnification. LPS increases the number of MHC-II immunoreactive microglial cells and induces a reactive phenotype in microglia, with thicker and shorter cell processes. SERMs revert the effect of LPS. Scale bar $100 \mu \mathrm{m}$. In the insets, the scale bar represents $25 \mu \mathrm{m}$. Adapted, with permission, from Tapia-Gonzalez S, Carrero P, Pernia O, GarciaSegura LM \& Diz-Chaves Y 2008 Selective oestrogen receptor (ER) modulators reduce microglia reactivity in vivo after peripheral inflammation: potential role of microglial ERs. Journal of Endocrinology 198 219-230. (C) 2008 Society for Endocrinology.

\section{A summary of the molecular mechanisms of neuroprotection by SERMs}

Figure 4 summarizes the mechanisms involved in the neuroprotective actions of SERMs that have been discussed in the previous sections. SERMs act on neurons and glial cells and regulate the activity of kinases, such as MAPK, PI3K, and Akt, which in turn regulate the activity of factors that control transcription, such as CREB and NF- $\kappa B$. In addition, SERMs regulate transcriptional activity of classical nuclear ERs. Therefore, SERMs exert multiple actions on signaling pathways that are involved in the modulation of synaptic transmission, the regulation of apoptosis, the control of oxidative stress, and the control of inflammation. Furthermore, actions of SERMs in endocrine glands may also contribute to their central actions by the modulation of the levels of neuroactive molecules such as $\beta$-endorphin and tetrahydroprogesterone or by the control of peripheral inflammation. All these actions of SERMs, exerted on neurons and glial cells, probably contribute to their effects on neuronal survival, mood, and cognition. However, the multiple mechanisms activated by SERMs may also represent a potential limitation for their use as neuroprotectants.

\section{Perspectives for the future}

Most of the studies showing neuroprotective actions of SERMs have focused on tamoxifen and raloxifene. These molecules are already in use in human clinic, which may facilitate their application as brain therapeutic drugs. However, tamoxifen and raloxifene have secondary effects that may limit their use and may block in some cases neuroprotective actions of $\mathrm{E}_{2}$. New SERMs, such as arzoxifene, bazedoxifene, lasofoxifene, and ospemifene, among others, need to be explored in experimental models of neurodegeneration. The few available studies with these SERMs indicate that bazedoxifene protects rat hippocampal neurons from excitotoxic cell death in vivo (Ciriza et al. 2004) and that ospemifene and bazedoxifene reduce the inflammatory response of astrocytes exposed to LPS (Cerciat et al. 2010). More studies are also needed to define the neuroprotective potential of natural SERMs (Azcoitia et al. 2006, Schreihofer \& Redmond 2009).

SERMs with better permeability of the blood-brain barrier need to be developed, since the access of these molecules to the central nervous system (CNS) may

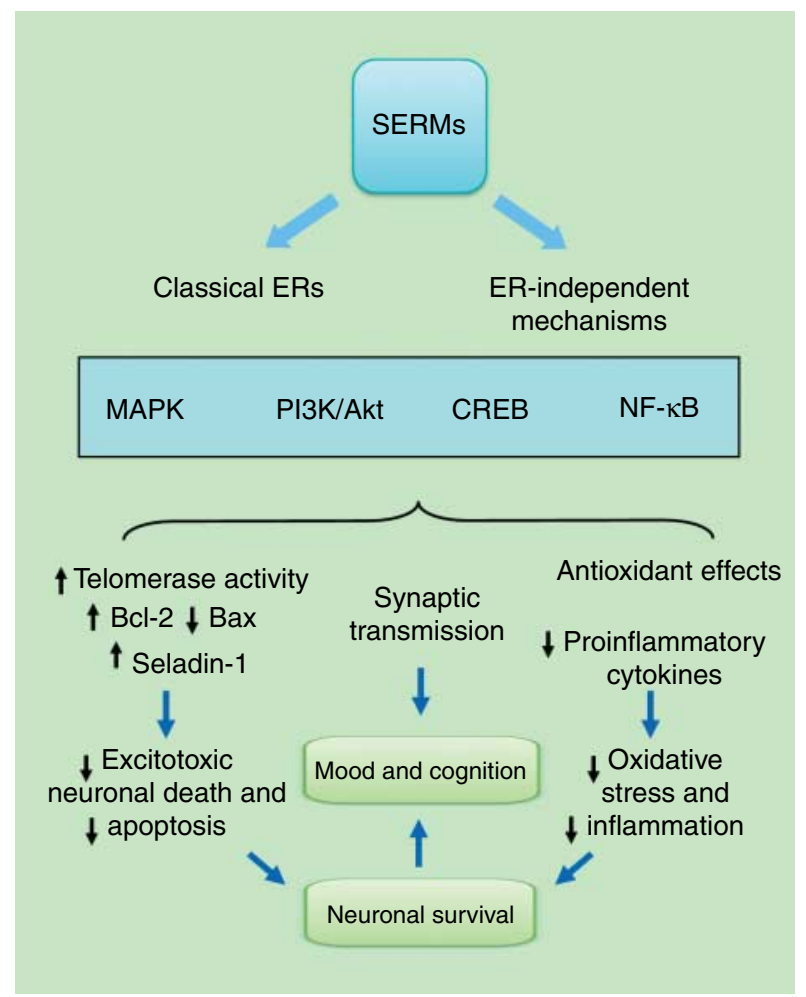

Figure 4 Summary of the molecular mechanisms involved in the neuroprotective effects of SERMs. SERMs act in the nervous system through classical ERs or by ER-independent mechanisms and activate a variety of signaling molecules, including MAPK,

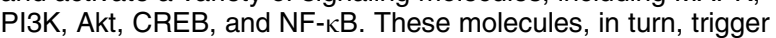
different coordinated mechanisms to promote neuronal survival and regulate mood and cognition. 
represent a limitation for their clinical application as neuroprotectants. Furthermore, new SERMs with preferential selectivity for activating estrogen mechanisms in brain and specifically designed to act as neuroprotectants are under development (Brinton 2004, Zhao et al. 2005). One of these molecules is $7 \alpha$-[(4R,8R)-4,8,12-trimethyltridecyl] estra-1,3,5-trien-3, $17 \beta$-diol, a hybrid structure of $\mathrm{E}_{2}$ and vitamin $\mathrm{E}$. This molecule binds to both $\operatorname{ER} \alpha$ and $\operatorname{ER} \beta$ and is neuroprotective in rat primary hippocampal neurons (Zhao et al. 2007). Other interesting molecules are estrogen non-feminizing analogs with phenol groups (Simpkins et al. 2005). Molecules such as $17 \alpha-\mathrm{E}_{2}$, ent- $\mathrm{E}_{2}$, 2-adamantylestrone, and ent-17-desoxyestradiol have been shown to be effective in the protection of neural tissue under different neurodegenerative conditions (Green et al. 2001, Liu et al. 2002, Yang et al. 2003, Jung et al. 2006, Wang et al. 2006).

In general, there is still poor knowledge of the precise molecular targets of SERMs in the nervous system. Although some key molecules have been identified, such as MAPK, PI3K/Akt, CREB, and $\mathrm{NF}-\kappa \mathrm{B}$, the molecular mechanisms involved in the neuroprotective actions of SERMs should be investigated with more detail in the different cellular populations of the nervous system. Ideally, SERMs with cellular specificity for neurons, astrocytes, oligodendrocytes, and microglia may promote cell-specific responses to decrease neuronal death, increase remyelination, enhance the production of neuroprotective growth factors by astrocytes, and reduce the chronic proinflammatory response of astrocytes and microglia.

\section{Declaration of interest}

The authors declare that there is no conflict of interest that could be perceived as prejudicing the impartiality of the research reported.

\section{Funding}

The authors acknowledge support from the Ministerio de Ciencia e Innovación, Spain (BFU2008-02950-C03-01/02).

\section{References}

Armagan G, Kanit L, Terek CM, Sozmen EY \& Yalcin A 2009 The levels of glutathione and nitrite-nitrate and the expression of Bcl-2 mRNA in ovariectomized rats treated by raloxifene against kainic acid. International Journal of Neuroscience 119 227-239. (doi:10.1080/ 00207450802330959)

Azcoitia I, Moreno A, Carrero P, Palacios S \& Garcia-Segura LM 2006 Neuroprotective effects of soy phytoestrogens in the rat brain. Gynecological Endocrinology 22 63-69. (doi:10.1080/ 09513590500519161)

Barreto G, Santos-Galindo M, Diz-Chaves Y, Pernía O, Carrero P, Azcoitia I \& Garcia-Segura LM 2009 Selective estrogen receptor modulators decrease reactive astrogliosis in the injured brain: effects of aging and prolonged depletion of ovarian hormones. Endocrinology 150 5010-5015. (doi:10.1210/en.2009-0352)

Barrett-Connor E, Cox DA, Song J, Mitlak B, Mosca L \& Grady D 2009 Raloxifene and risk for stroke based on the framingham stroke risk score. American Journal of Medicine 122 754-761. (doi:10.1016/ j.amjmed.2009.01.033)

Bebo BF, Dehghani B, Foster S, Kurniawan A, Lopez FJ \& Sherman LS 2009 Treatment with selective estrogen receptor modulators regulates myelin specific T-cells and suppresses experimental autoimmune encephalomyelitis. Glia 57 777-790. (doi:10.1002/ glia.20805)

Belandia B \& Parker MG 2003 Nuclear receptors: a rendezvous for chromatin remodeling factors. Cell 114 277-280. (doi:10.1016/ S0092-8674(03) 00599-3)

Benvenuti S, Luciani P, Vannelli GB, Gelmini S, Franceschi E, Serio M \& Peri A 2005 Estrogen and selective estrogen receptor modulators exert neuroprotective effects and stimulate the expression of selective Alzheimer's disease indicator-1, a recently discovered antiapoptotic gene, in human neuroblast long-term cell cultures. Journal of Clinical Endocrinology and Metabolism 90 1775-1782. (doi:10.1210/jc.2004-0066)

Bernardi F, Pluchino N, Stomati M, Pieri M \& Genazzani AR 2003 CNS: sex steroids and SERMs. Annals of the New York Academy of Sciences 997 378-388. (doi:10.1196/annals.1290.041)

Biewenga E, Cabell L \& Audesirk T 2005 Estradiol and raloxifene protect cultured SN4741 neurons against oxidative stress. Neuroscience Letters 373 179-183. (doi:10.1016/j.neulet.2004.09.067)

Bourque M, Liu B, Dluzen DE \& Di Paolo T 2007 Tamoxifen protects male mice nigrostriatal dopamine against methamphetamine-induced toxicity. Biochemical Pharmacology 74 1413-1423. (doi:10.1016/j.bcp.2007.07.009)

Breuer B \& Anderson R 2000 The relationship of tamoxifen with dementia, depression, and dependence in activities of daily living in elderly nursing home residents. Women's Health 31 71-85. (doi:10. 1300/J013v31n01_05)

Brinton RD 2004 Requirements of a brain selective estrogen: advances and remaining challenges for developing a NeuroSERM. Journal of Alzheimer's Disease 6 (6 Supplement) S27-S35.

Brzozowski AM, Pike AC, Dauter Z, Hubbard RE, Bonn T, Engstrom O, Ohman L, Greene GL, Gustafsson JA \& Carlquist M 1997 Molecular basis of agonism and antagonism in the estrogen receptor. Nature 389 753-758. (doi:10.1038/39645)

Callier S, Morissette M, Grandbois M, Pelaprat D \& Di Paolo T 2001 Neuroprotective properties of $17 \beta$-estradiol, progesterone, and raloxifene in MPTP C57Bl/6 mice. Synapse 41 131-138. (doi:10. 1002/syn.1067)

Carranza-Lira S, MacGregor-Gooch AL \& Sarachaga-Osterwalder M 2004 Mood modifications with raloxifene and continuous estrogen plus progestin hormone therapy. International Journal of Fertility and Women's Medicine 49 120-122.

Cerciat M, Unkila M, Garcia-Segura LM \& Arevalo MA 2010 Selective estrogen receptor modulators decrease the production of interleukin- 6 and interferon- $\gamma$-inducible protein- 10 by astrocytes exposed to inflammatory challenge in vitro. Glia 58 93-102. (doi:10.1002/glia.20904)

Ciriza I, Carrero P, Azcoitia I, Lundeen SG \& Garcia-Segura LM 2004 Selective estrogen receptor modulators protect hippocampal neurons from kainic acid excitotoxicity: differences with the effect of estradiol. Journal of Neurobiology 61 209-221. (doi:10.1002/neu.20043)

Cyr M, Landry M \& Di Paolo T 2000 Modulation by estrogen-receptor directed drugs of 5-hydroxytryptamine-2A receptors in rat brain. Neuropsychopharmacology 23 69-78. (doi:10.1016/S0893133X(00) 00085-3)

Debess J, Riis JØ, Engebjerg MC \& Ewertz M 2010 Cognitive function after adjuvant treatment for early breast cancer: a population-based longitudinal study. Breast Cancer Research and Treatment 121 91-100. (doi:10.1007/s10549-010-0756-8) 
Dhandapani KM \& Brann DW 2002 Protective effects of estrogen and selective estrogen receptor modulators in the brain. Biology of Reproduction 67 1379-1385. (doi:10.1095/biolreprod.102.003848)

DonCarlos LL, Azcoitia I \& Garcia-Segura LM 2009 Neuroprotective actions of selective estrogen receptor modulators. Psychoneuroendocrinology 34 (Supplement 1) S113-S122. (doi:10.1016/j.psyneuen. 2009.04.012)

Dowers TS, Qin ZH, Thatcher GR \& Bolton JL 2006 Bioactivation of selective estrogen receptor modulators (SERMs). Chemical Research in Toxicology 19 1125-1137. (doi:10.1021/tx060126v)

Du B, Ohmichi M, Takahashi K, Kawagoe J, Ohshima C, Igarashi H, Mori-Abe A, Saitoh M, Ohta T, Ohishi A et al. 2004 Both estrogen and raloxifene protect against $\beta$-amyloid-induced neurotoxicity in estrogen receptor $\alpha$-transfected PC12 cells by activation of telomerase activity via Akt cascade. Journal of Endocrinology 183 605-615. (doi:10.1677/joe.1.05775)

Einat H, Yuan P, Szabo ST, Dogra S \& Manji HK 2007 Protein kinase C inhibition by tamoxifen antagonizes manic-like behavior in rats: implications for the development of novel therapeutics for bipolar disorder. Neuropsychobiology 55 123-131. (doi:10.1159/000106054)

Feng Y, Fratkins JD \& LeBlanc MH 2004 Treatment with tamoxifen reduces hypoxic-ischemic brain injury in neonatal rats. European Journal of Pharmacology 484 65-74. (doi:10.1016/ j.ejphar.2003.10.048)

Florio P, Quirici B, Casarosa E, Lombardi I, Luisi M, Genazzani AD, Petraglia F \& Gennazzani AR 2001 Neuroendocrine effects of raloxifene hydrochloride in postmenopausal women. Gynecological Endocrinology 15 359-366. (doi:10.1080/gye.15.5.359.366)

Garcia-Segura LM \& Balthazart J 2009 Steroids and neuroprotection: new advances. Frontiers in Neuroendocrinology 30 v-ix. (doi:10.1016/ j.yfrne.2009.04.006)

Genazzani AR, Bernardi F, Stomati M, Rubino S, Giardina L, Luisi S, Monteleone P, Genazzani AD, Luisi M \& Petraglia F 1999 Raloxifene analog LY 117018 effects on central and peripheral $\beta$-endorphin. Gynecological Endocrinology 13 249-258. (doi:10.3109/ 09513599909167563)

Genazzani AR, Bernardi F, Stomati M, Monteleone P, Luisi S, Rubino S, Farzati A, Casarosa E, Luisi M \& Petraglia F 2000 Effects of estradiol and raloxifene analog on brain, adrenal and serum allopregnanolone content in fertile and ovariectomized female rats. Neuroendocrinology 72 162-170. (doi:10.1159/000054583)

Genazzani AR, Lombardi I, Borgioli G, di Buono I, Casarosa E, Gambacciani M, Palumbo M, Genazzani AD \& Luisi M 2003 Adrenal function under long-term raloxifene administration increases $\beta$-endorphin and tetrahydroprogesterone. Gynecological Endocrinology 17 159-168.

Goekoop R, Duschek EJ, Knol DL, Barkhof F, Netelenbos C, Scheltens P \& Rombouts SA 2005 Raloxifene exposure enhances brain activation during memory performance in healthy elderly males; its possible relevance to behavior. NeuroImage 25 63-75. (doi:10.1016/j.neuroimage.2004.11.012)

Goekoop R, Barkhof F, Duschek EJ, Netelenbos C, Knol DL, Scheltens P \& Rombouts SA 2006 Raloxifene treatment enhances brain activation during recognition of familiar items: a pharmacological fMRI study in healthy elderly males. Neuropsychopharmacology 31 1508-1518. (doi:10.1038/sj.npp.1300956)

Grandbois M, Morissette M, Callier S \& Di Paolo T 2000 Ovarian steroids and raloxifene prevent MPTP-induced dopamine depletion in mice. Neuroreport 11 343-346. (doi:10.1097/00001756200002070-00024)

Green PS, Yang SH, Nilsson KR, Kumar AS, Covey DF \& Simpkins JW 2001 The nonfeminizing enantiomer of $17 \beta$-estradiol exerts protective effects in neuronal cultures and a rat model of cerebral ischemia. Endocrinology 142 400-406. (doi:10.1210/en.142.1.400)

Grigoriadis S, Kennedy SH, Srinivisan J, McIntyre RS \& Fulton K 2005 Antidepressant augmentation with raloxifene. Journal of Clinical Psychopharmacology 25 96-98. (doi:10.1097/01.jcp.0000150230. 07243.52)
Jacobsen DE, Samson MM, Emmelot-Vonk MH \& Verhaar HJ 2010 Raloxifene improves verbal memory in late postmenopausal women: a randomized, double-blind, placebo-controlled trial. Menopause 17 309-314. (doi:10.1097/gme.0b013e3181bd54df)

Jung ME, Wilson AM \& Simpkins JW 2006 A nonfeminizing estrogen analog protects against ethanol withdrawal toxicity in immortalized hippocampal cells. Journal of Pharmacology and Experimental Therapeutics 319 543-550. (doi:10.1124/jpet.106.103630)

Kimelberg HK 2008 Tamoxifen as a powerful neuroprotectant in experimental stroke and implications for human stroke therapy. Recent Patents on CNS Drug Discovery 3 104-108. (doi:10.2174/ 157488908784534603)

Kimelberg HK, Jin Y, Charniga C \& Feustel PJ 2003 Neuroprotective activity of tamoxifen in permanent focal ischemia. Journal of Neurosurgery 99 138-142. (doi:10.3171/jns.2003.99.1.0138)

Klinge CM 2000 Estrogen receptor interaction with co-activators and co-repressors. Steroids 65 227-251. (doi:10.1016/S0039128X(99)00107-5)

Kokiko ON, Murashov AK \& Hoane MR 2006 Administration of raloxifene reduces sensorimotor and working memory deficits following traumatic brain injury. Behavioural Brain Research 170 233-240. (doi:10.1016/j.bbr.2006.02.026)

Konyalioglu S, Durmaz G \& Yalcin A 2007 The potential antioxidant effect of raloxifene treatment: a study on heart, liver and brain cortex of ovariectomized female rats. Cell Biochemistry and Function 25 259-266. (doi:10.1002/cbf.1328)

Kulkarni J, Garland KA, Scaffidi A, Headey B, Anderson R, de Castella A, Fitzgerald P \& Davis SR 2006 A pilot study of hormone modulation as a new treatment for mania in women with bipolar affective disorder. Psychoneuroendocrinology 31 543-547. (doi:10.1016/j.psyneuen.2005. 11.001)

Kulkarni J, Gurvich C, Lee SJ, Gilbert H, Gavrilidis E, de Castella A, Berk M, Dodd S, Fitzgerald PB \& Davis SR 2010 Piloting the effective therapeutic dose of adjunctive selective estrogen receptor modulator treatment in postmenopausal women with schizophrenia. Psychoneuroendocrinology 35 1142-1147. (doi:10.1016/j.psyneuen. 2010.01.014)

Landry M, Levesque D \& Di Paolo T 2002 Estrogenic properties of raloxifene, but not tamoxifen, on D2 and D3 dopamine receptors in the rat forebrain. Neuroendocrinology 76 214-222. (doi:10.1159/ 000065951)

Latourelle JC, Dybdahl M, Destefano AL, Myers RH \& Lash TL 2010 Risk of Parkinson's disease after tamoxifen treatment. $B M C$ Neurology 10 23. (doi:10.1186/1471-2377-10-23)

Lee ES, Sidoryk M, Jiang H, Yin Z \& Aschner M 2009 $a$ Estrogen and tamoxifen reverse manganese-induced glutamate transporter impairment in astrocytes. Journal of Neurochemistry 110 530-544. (doi:10.1111/j.1471-4159.2009.06105.x)

Lee ES, Yin Z, Milatovic D, Jiang H \& Aschner M $2009 b$ Estrogen and tamoxifen protect against Mn-induced toxicity in rat cortical primary cultures of neurons and astrocytes. Toxicological Sciences 110 156-167. (doi:10.1093/toxsci/kfp081)

Lei DL, Long JM, Hengemihle J, O'Neill J, Manaye KF, Ingram DK \& Mouton PR 2003 Effects of estrogen and raloxifene on neuroglia number and morphology in the hippocampus of aged female mice. Neuroscience 121 659-666. (doi:10.1016/S0306-4522(03)00245-8)

Liu R, Yang SH, Perez E, Yi KD, Wu SS, Eberst K, Prokai L, ProkaiTatrai K, Cai ZY, Covey DF et al. 2002 Neuroprotective effects of a novel non-receptor-binding estrogen analogue: in vitro and in vivo analysis. Stroke 33 2485-2491. (doi:10.1161/01.STR.0000030317. 43597.C8)

Liu JL, Tian DS, Li ZW, Qu WS, Zhan Y, Xie MJ, Yu ZY, Wang W \& Wu G 2010 Tamoxifen alleviates irradiation-induced brain injury by attenuating microglial inflammatory response in vitro and in vivo. Brain Research 1316 101-111. (doi:10.1016/j.brainres.2009.12.055)

McKenna NP \& O'Malley BO 2002 Combinatorial control of gene expression by nuclear receptors and coregulators. Cell 108 465-474. (doi:10.1016/S0092-8674(02)00641-4) 
McMurray R, Islamov R \& Murashov AK 2003 Raloxifene analog LY117018 enhances the regeneration of sciatic nerve in ovariectomized female mice. Brain Research 980 140-145. (doi:10.1016/ S0006-8993(03) 02984-6)

Mehta SH, Dhandapani KM, De Sevilla LM, Webb RC, Mahesh VB \& Brann DW 2003 Tamoxifen, a selective estrogen receptor modulator, reduces ischemic damage caused by middle cerebral artery occlusion in the ovariectomized female rat. Neuroendocrinology $\mathbf{7 7}$ 44-50. (doi:10.1159/000068332)

Mickley KR \& Dluzen DE 2004 Dose-response effects of estrogen and tamoxifen upon methamphetamine-induced behavioral responses and neurotoxicity of the nigrostriatal dopaminergic system in female mice. Neuroendocrinology 79 305-316. (doi:10.1159/ 000079710)

Moreira PI, Custódio JB, Oliveira CR \& Santos MS 2004 Hydroxytamoxifen protects against oxidative stress in brain mitochondria. Biochemical Pharmacology 68 195-204. (doi:10.1016/j.bcp.2004.03. 019)

Moreira PI, Custódio JB, Oliveira CR \& Santos MS 2005 Brain mitochondrial injury induced by oxidative stress-related events is prevented by tamoxifen. Neuropharmacology 48 435-447. (doi:10. 1016/j.neuropharm.2004.10.012)

Morissette M, Al Sweidi S, Callier S \& Di Paolo T 2008 Estrogen and SERM neuroprotection in animal models of Parkinson's disease. Molecular and Cellular Endocrinology 290 60-69. (doi:10.1016/j.mce. 2008.04.008)

Mosca L, Grady D, Barrett-Connor E, Collins P, Wenger N, Abramson BL, Paganini-Hill A, Geiger MJ, Dowsett SA, Amewou-Atisso M et al. 2009 Effect of raloxifene on stroke and venous thromboembolism according to subgroups in postmenopausal women at increased risk of coronary heart disease. Stroke 40 147-155. (doi:10.1161/ STROKEAHA.108.518621)

Neele SJ, Evertz R, Genazzani AR, Luisi M \& Netelenbos C 2002 Raloxifene treatment increases plasma levels of $\beta$-endorphin in postmenopausal women: a randomized, placebo-controlled study. Fertility and Sterility 77 1110-1117. (doi:10.1016/S00150282(02)03108-4)

Nilsen J, Mor G \& Naftolin F 1998 Raloxifene induces neurite outgrowth in estrogen receptor positive PC12 cells. Menopause 5 211-216. (doi:10.1097/00042192-199805040-00005)

Norris JD, Paige LA, Christensen DJ, Chang CY, Huacani MR, Fan D, Hamilton PT, Fowlkes DM \& McDonnell DP 1999 Peptide antagonists of the human estrogen receptor. Science 285 744-746. (doi:10.1126/science.285.5428.744)

O'Neill K, Chen S \& Diaz Brinton R 2004 Impact of the selective estrogen receptor modulator, tamoxifen, on neuronal outgrowth and survival following toxic insults associated with aging and Alzheimer's disease. Experimental Neurology 188 268-278. (doi:10. 1016/j.expneurol.2004.01.014)

Paganini-Hill A \& Clark LJ 2000 Preliminary assessment of cognitive function in breast cancer patients treated with tamoxifen. Breast Cancer Research and Treatment 64 165-176. (doi:10.1023/ A:1006426132338)

Paige LA, Christensen DJ, Grøn H, Norris JD, Gottlin EB, Padilla KM, Chang CY, Ballas LM, Hamilton PT \& McDonnell DP 1999 Estrogen receptor (ER) modulators each induce distinct conformational changes in ERa and ERb. PNAS 96 3999-4004. (doi:10.1073/pnas. 96.7.3999)

Palmer JL, Trotter T, Joy AA \& Carlson LE 2008 Cognitive effects of Tamoxifen in pre-menopausal women with breast cancer compared to healthy controls. Journal of Cancer Survivorship 2 275-282. (doi:10.1007/s11764-008-0070-1)

Phillips KA, Ribi K, Sun Z, Stephens A, Thompson A, Harvey V, Thürlimann B, Cardoso F, Pagani O, Coates AS et al. 2010 Cognitive function in postmenopausal women receiving adjuvant letrozole or tamoxifen for breast cancer in the BIG 1-98 randomized trial. Breast 19 388-395. (doi:10.1016/j.breast.2010. 03.025)
Rossberg MI, Murphy SJ, Traystman RJ \& Hurn PD 2000 LY353381.HCl, a selective estrogen receptor modulator, and experimental stroke. Stroke 31 3041-3046.

Sánchez MG, Bourque M, Morissette M \& Di Paolo T 2010 Steroids-dopamine interactions in the pathophysiology and treatment of CNS disorders. CNS Neuroscience and Therapeutics $\mathbf{1 6}$ e43-e71. (doi:10.1111/j.1755-5949.2010.00163.x)

Schilder CM, Seynaeve C, Beex LV, Boogerd W, Linn SC, Gundy CM, Huizenga HM, Nortier JW, van de Velde CJ, van Dam FS et al. 2010 Effects of tamoxifen and exemestane on cognitive functioning of postmenopausal patients with breast cancer: results from the neuropsychological side study of the tamoxifen and exemestane adjuvant multinational trial. Journal of Clinical Oncology 28 1294-1300. (doi:10.1200/JCO.2008.21.3553)

Schreihofer DA \& Redmond L 2009 Soy phytoestrogens are neuroprotective against stroke-like injury in vitro. Neuroscience $\mathbf{1 5 8}$ 602-609. (doi:10.1016/j.neuroscience.2008.10.003)

Sharma K \& Mehra RD 2008 Long-term administration of estrogen or tamoxifen to ovariectomized rats affords neuroprotection to hippocampal neurons by modulating the expression of Bcl-2 and Bax. Brain Research 1204 1-15. (doi:10.1016/j.brainres.2008. 01.080)

Sharma K, Mehra RD, Dhar P \& Vij U 2007 Chronic exposure to estrogen and tamoxifen regulates synaptophysin and phosphorylated cAMP response element-binding (CREB) protein expression in CAl of ovariectomized rat hippocampus. Brain Research 1132 10-19. (doi:10.1016/j.brainres.2006.11.027)

Shilling V, Jenkins V, Fallowfield L \& Howell T 2003 The effects of hormone therapy on cognition in breast cancer. Journal of Steroid Biochemistry and Molecular Biology 86 405-412. (doi:10.1016/j.jsbmb. 2003.07.001)

Simpkins JW, Wen Y, Perez E, Yang S \& Wang X 2005 Role of nonfeminizing estrogens in brain protection from cerebral ischemia: an animal model of Alzheimer's disease neuropathology. Annals of the New York Academy of Sciences 1052 233-242. (doi:10. 1196/annals.1347.019)

Smith LJ, Henderson JA, Abell CW \& Bethea CL 2004 Effects of ovarian steroids and raloxifene on proteins that synthesize, transport, and degrade serotonin in the raphe region of macaques. Neuropsychopharmacology 29 2035-2045. (doi:10.1038/sj.npp. 1300510)

Strickler R, Stovall DW, Merritt D, Shen W, Wong M \& Silfen SL 2000 Raloxifene and estrogen effects on quality of life in healthy postmenopausal women: a placebo-controlled randomized trial. Obstetrics and Gynecology 96 359-365. (doi:10.1016/S00297844(00) 00937-6)

Sugiyama N, Sasayama D \& Amano N 2007 Remarkable antidepressant augmentation effect of raloxifene, a selective estrogen receptor modulator, in a partial responder to fluvoxamine: a case report. Journal of Clinical Psychiatry 68 636-637. (doi:10.4088/JCP. v68n0423d)

Suuronen T, Nuutinen T, Huuskonen J, Ojala J, Thornell A \& Salminen A 2005 Anti-inflammatory effect of selective estrogen receptor modulators (SERMs) in microglial cells. Inflammation Research 54 194-203. (doi:10.1007/s00011-005-1343-z)

Tapia-Gonzalez S, Carrero P, Pernia O, Garcia-Segura LM \& Diz-Chaves Y 2008 Selective oestrogen receptor (ER) modulators reduce microglia reactivity in vivo after peripheral inflammation: potential role of microglial ERs. Journal of Endocrinology 198 219-230. (doi:10.1677/JOE-07-0294)

Tian DS, Liu JL, Xie MJ, Zhan Y, Qu WS, Yu ZY, Tang ZP, Pan DJ \& Wang W 2009 Tamoxifen attenuates inflammatory-mediated damage and improves functional outcome after spinal cord injury in rats. Journal of Neurochemistry 109 1658-1667. (doi:10.1111/j.14714159.2009.06077.x)

Wakade C, Khan MM, De Sevilla LM, Zhang QG, Mahesh VB \& Brann DW 2008 Tamoxifen neuroprotection in cerebral ischemia 
involves attenuation of kinase activation and superoxide production and potentiation of mitochondrial superoxide dismutase. Endocrinology 149 367-379. (doi:10.1210/en.2007-0899)

Walf AA \& Frye CA 2010 Raloxifene and/or estradiol decrease anxietylike and depressive-like behavior, whereas only estradiol increases carcinogen-induced tumorigenesis and uterine proliferation among ovariectomized rats. Behavioural Pharmacology 21 231-240. (doi:10.1097/FBP.0b013e32833a5cb0)

Wang X, Dykens JA, Perez E, Liu R, Yang S, Covey DF \& Simpkins JW 2006 Neuroprotective effects of $17 \beta$-estradiol and nonfeminizing estrogens against $\mathrm{H}_{2} \mathrm{O}_{2}$ toxicity in human neuroblastoma SK-N-SH cells. Molecular Pharmacology 70 395-404. (doi:10.1124/mol.106. 023986)

Wu X, Glinn MA, Ostrowski NL, Su Y, Ni B, Cole HW, Bryant HU \& Paul SM 1999 Raloxifene and estradiol benzoate both fully restore hippocampal choline acetyltransferase activity in ovariectomized rats. Brain Research 847 98-104. (doi:10.1016/S00068993(99)02062-4)

Yaffe K, Krueger K, Cummings SR, Blackwell T, Henderson VW, Sarkar S, Ensrud K \& Grady D 2005 Effect of raloxifene on prevention of dementia and cognitive impairment in older women: the multiple outcomes of raloxifene evaluation (MORE) randomized trial. American Journal of Psychiatry 162 683-690. (doi:10.1176/appi.ajp.162.4.683)

Yang SH, Liu R, Wu SS \& Simpkins JW 2003 The use of estrogens and related compounds in the treatment of damage from cerebral ischemia. Annals of the New York Academy of Sciences 1007 101-107. (doi:10.1196/annals.1286.010)
Zarate CA, Singh JB, Carlson PJ, Quiroz J, Jolkovsky L, Luckenbaugh DA \& Manji HK 2007 Efficacy of a protein kinase C inhibitor (tamoxifen) in the treatment of acute mania: a pilot study. Bipolar Disorders 9 561-570. (doi:10.1111/j.1399-5618.2007.00530.x)

Zhang Y, Milatovic D, Aschner M, Feustel PJ \& Kimelberg HK 2007 Neuroprotection by tamoxifen in focal cerebral ischemia is not mediated by an agonist action at estrogen receptors but is associated with antioxidant activity. Experimental Neurology 204 819-827. (doi:10.1016/j.expneurol.2007.01.015)

Zhang H, Xie M, Schools GP, Feustel PF, Wang W, Lei T, Kimelberg HK \& Zhou M 2009 Tamoxifen mediated estrogen receptor activation protects against early impairment of hippocampal neuron excitability in an oxygen/glucose deprivation brain slice ischemia model. Brain Research 1247 196-211. (doi:10.1016/j.brainres.2008.10.015)

Zhao L, O'Neill K \& Diaz Brinton R 2005 Selective estrogen receptor modulators (SERMs) for the brain: current status and remaining challenges for developing NeuroSERMs. Brain Research. Brain Research Reviews 49 472-493. (doi:10.1016/j.brainresrev.2005. 01.009)

Zhao L, Jin C, Mao Z, Gopinathan MB, Rehder K \& Brinton RD 2007 Design, synthesis, and estrogenic activity of a novel estrogen receptor modulator - a hybrid structure of $17 \beta$-estradiol and vitamin $\mathrm{E}$ in hippocampal neurons. Journal of Medicinal Chemistry $\mathbf{5 0}$ 4471-4481. (doi:10.1021/jm070546x)

Received in final form 14 October 2010

Accepted 9 November 2010

Made available online as an Accepted Preprint 11 November 2010 